\title{
Clinical Utility and Concordance of Upper Urinary Tract Cytology and Biopsy in Predicting Clinicopathologic Features of Upper Urinary Tract Urothelial Carcinoma
}

Caroline Talsma Simon MD*a, Stephanie L. Skala MD*a, Alon Z. Weizer MD ${ }^{c}$, Sapan N. Ambani MD ${ }^{c}$, Arul M. Chinnaiyan MD, PhD ${ }^{a, c, d, e, f, g}$, Ganesh Palapattu MD ${ }^{c}$, Khaled Hafez MD ${ }^{c}$, Martin J. Magers MD ${ }^{b}$, Samuel D. Kaffenberger $\mathrm{MD}^{c}$, Daniel E. Spratt $\mathrm{MD}^{\mathrm{h}}$, Jeffrey S. Montgomery $\mathrm{MD}^{\mathrm{c}}$, Todd M. Morgan MD $\mathrm{PhD}^{\mathrm{c}}$, Aaron M. Udager MD PhD ${ }^{\mathrm{a}}$, Madelyn Lew MD ${ }^{\mathrm{a}}$, Rohit Mehra MD ${ }^{\mathrm{a}, \mathrm{d}, \mathrm{g}}$

${ }^{a}$ Department of Pathology, University of Michigan, 2800 Plymouth Road, Building 35, Ann Arbor, MI 48109, USA

${ }^{\mathrm{b}}$ Department of Pathology, Indiana University School of Medicine, 635 Barnhill Drive, Indianapolis, IN, 46202, USA

${ }^{\mathrm{C}}$ Department of Urology, University of Michigan, $1500 \mathrm{E}$. Medical Center Drive, Ann Arbor, MI, 48109, USA

d Michigan Center for Translational Pathology, 5309 CCC 5940, 1500 E. Medical Center Drive, Ann Arbor, MI, 48109, USA

${ }^{\mathrm{e}}$ Department of Computational Medicine and Bioinformatics, University of Michigan, Room 2017, Palmer Commons, 100 Washtenaw Ave, Ann Arbor, MI, 48109, USA

${ }^{\mathrm{f}}$ Howard Hughes Medical Institute, University of Michigan Medical School, Ann Arbor, 1500 E Medical Center Drive, MI

${ }^{\mathrm{g}}$ Comprehensive Cancer Center, University of Michigan Medical School, 1500 E Medical Center Drive, Ann Arbor, MI, 48109, USA

h Department of Radiation Oncology, University of Michigan, UH B2C490, 1500 E. Medical Center Drive, Ann Arbor, MI, 48109, USA

*These authors contributed equally.

\section{Corresponding author at:}

Rohit Mehra, M.D.

Associate Professor, Department of Pathology, University of Michigan

Member, Michigan Center for Translational Pathology and Comprehensive Cancer Center

Director, Michigan Legacy Tissue Program

University of Michigan Department of Pathology

2800 Plymouth Road

Building 35

Ann Arbor, MI 48109

Email: mrohit@med.umich.edu

Phone: 1-734-232-3743

Fax: 1-734-763-4095

Running Title: Upper Urinary Tract Cytology/Biopsy and Resection Concordance

Keywords: upper tract urothelial carcinoma; upper urinary tract biopsy; upper urinary tract cytology

\section{Conflict of interest: The authors have no relationships with, or finical interest in, any commercial companies pertaining to this article}

Funding/support: Not applicable.

This is the author's manuscript of the article published in final edited form as:

Simon, C. T., Skala, S. L., Weizer, A. Z., Ambani, S. N., Chinnaiyan, A. M., Palapattu, G., ... Mehra, R. (2018).

Clinical utility and concordance of upper urinary tract cytology and biopsy in predicting Clinicopathologic features of upper urinary tract urothelial carcinoma. Human Pathology. https://doi.org/10.1016/j.humpath.2018.11.021 


\begin{abstract}
:
$5 \%$ of urothelial carcinoma occurs in the upper urinary tract (UUT), a challenging location to biopsy. We aim to evaluate concordance between biopsy, cytology, and resection specimens in a large upper tract urothelial carcinoma (UTUC) cohort.117 UTUC resections with UUT biopsy and/or cytology specimens from 2000-2016 were retrieved; pathologic material was re-reviewed, evaluated for concordance, and correlated with clinical information. 14\% pre-operative biopsies, including 8 from renal pelvis and 6 from ureter, lacked neoplastic diagnoses. 77\% diagnostic biopsies included subepithelial tissue; $11 \%$ demonstrated reclassification of grade and $30 \%$ demonstrated reclassification of invasion status. $26 \%$ of renal pelvis UTUC and $36 \%$ ureter UTUC were invasive only on resection. Of 18 UTUC reclassified from noninvasive high-grade papillary urothelial carcinoma (HGPUC) to invasive HGPUC, $39 \%$ had prior radical cystectomy (versus $8 \%$ invasive UTUC and $11 \%$ noninvasive UTUC with concordant biopsies). Most highgrade UTUC (88\%) and some low-grade UTUC (58\%) resections had abnormal cytology results. Biopsyresection pairs with concordant invasion status and pairs with discordant invasion status showed similar rates of recurrence ( $38 \%$ versus $38 \%$ ) and metastasis ( $25 \%$ versus $27 \%$ ). $14 \%$ of UUT biopsies lacked diagnostic neoplastic material. Grade concordance between biopsy and resection was high (89\%), but $30 \%$ of cases showed invasion only on resection. Subepithelial tissue was less commonly present in ureter biopsies, particularly from mid or proximal ureter. UTUC in patients with prior cystectomy were more likely to show invasion on resection but not biopsy.
\end{abstract}




\section{Introduction}

Upper tract (renal pelvis, ureter) urothelial carcinoma (UTUC) accounts for approximately $5 \%$ of urothelial carcinomas. [1,2] Diagnosis of urothelial carcinoma (UCa) often requires biopsy and/or cytology confirmation with demonstration of malignant cells. Urinary bladder lesions can be relatively easily accessed for biopsy during cystoscopy and bladder washing and voided urine cytology specimens most directly reflect the status of urothelium in the bladder on cytology specimens. Voided urine cytology has been demonstrated to be positive in approximately $25-72 \%$ of bladder UCa cases $[3,4]$; inclusion of suspicious diagnoses increases sensitivity to 89\%. [5] In contrast, visualization of and access to the upper urinary tract is more technically challenging. [6] Given the greater level of difficulty involved in the detection and sampling of UTUC, it is not surprising that a significant subset of UTUC biopsies may demonstrate inadequate tissue for a pathologic diagnosis. [7, 8] Similarly, the sensitivity of selective upper urinary tract cytology has been estimated at $55-81 \% .[9,10]$

In patients with high-risk UTUC, regardless of location, the first line treatment option in the majority of cases is a radical nephroureterectomy (RNU). [2] Classification of UTUC as high-risk is based on the presence of any concerning clinical/radiologic factors including the presence of hydronephrosis, tumor size $>2 \mathrm{~cm}$, multifocal disease, previous radical cystectomy for bladder cancer, or pathologic factors including high-grade cytology or upper tract biopsy with diagnosis of high-grade carcinoma and presence of variant histology. [2] Detection of hydronephrosis/hydroureter on imaging is also thought to correlate with muscular invasion.

There are few studies which have assessed the clinical accuracy of upper urinary tract biopsy and cytology in aiding clinical decision-making for UTUC patients. A large number of UTUC have been resected at Michigan Medicine, and in-house pre-operative upper urinary tract biopsy and cytology specimens are often obtained prior to surgery. Here, we aimed to evaluate the clinicopathologic features of a cohort with biopsy, cytology, and resection material in a large cohort of UTUC in order to assess concordance between different diagnostic modalities, as well as the effect of such concordance on clinical outcomes.

\section{Materials and Methods}

\subsection{Cohort Selection}

With Institutional Review Board approval, cases of upper urinary tract urothelial carcinoma with radical nephroureterectomy (RNU) or ureterectomy (UT) performed between 2000 and 2016 were retrospectively identified from the surgical pathology archive at Michigan Medicine. Only cases with ipsilateral pre-operative upper urinary tract biopsy and/or selective cytology available for review were included, resulting in a final cohort of 117 surgical resections (RNU or UT) from 114 patients.

\subsection{Review of Patient Material}

The biopsy, cytology, and surgical resection materials were re-reviewed by a genitourinary pathologist (RM), a cytopathologist (ML), and two pathology residents (CTS and SLS). Pathologic features assessed in biopises included tumor type, grade, and presence of invasion into subepithelial connective tissue or deeper. Biopsies designated as non-neoplastic include both negative and non-diagnostic biopsies. The 
pathologic features assessed in resections (RNU and UT) included tumor type, grade, stage, presence of divergent differentiation, lymph node status, margin status, and presence of angiolymphatic invasion or urothelial carcinoma in situ. Cytology specimens were reviewed for confirmation of diagnosis, as well as upper tract origin (per requisition form).

\subsection{Biopsy, cytology and Resection concordance}

Pre-operative endoscopic biopsy diagnoses and surgical resection diagnoses were assessed for concordance with respect to grade, presence of absence of invasion, and presence of absence of divergent differentiation, with the RNU or UT resection considered to be the "gold standard."

\subsection{Patient treatment, follow-up and outcomes}

Patient demographics, receipt of neoadjuvant chemotherapy or adjuvant therapy of any kind, and clinical follow-up including recurrence, distant metastasis, and death were also documented.

\section{Results}

\subsection{Cohort Summary}

The cohort of 114 patients included 85 (85/114, 75\%) male and 29 (29/114, 25\%) female patients with a mean age of 70 years (range 47-94 years). Of the 117 resections from these 114 patients, 101 resections (101/117, 86\%) from 97 patients had corresponding ipsilateral preoperative biopsy specimens available for review. Fifty-four resections $(54 / 117,46 \%)$ from 53 patients had ipsilateral preoperative upper tract cytology specimens available for review. Twenty patients had previously undergone cystectomy for primary bladder urothelial carcinoma, and one additional patient underwent cystectomy at the same time as upper tract resection. Clinical information for the cohort is summarized in Table 1. Eighteen $(18 / 117,15 \%)$ resections lacked any in-house pre-operative pathologic material (biopsy or cytology) diagnostic of carcinoma. Of these eighteen patients, three had only negative cytology and no biopsy $(3 / 18,17 \%), 3$ had only atypical cytology and no biopsy $(3 / 18,17 \%), 1$ negative cytology and no neoplastic diagnosis on biopsy $(1 / 18,6 \%), 1$ had atypical cytology and no neoplastic diagnosis on biopsy $(1 / 18,6 \%)$, and 10 had no cytology and no neoplastic diagnosis on biopsy (10/18, 56\%).

\subsection{Decision for Resection}

Review of clinical notes demonstrated that the results of upper tract biopsy and/or cytology specimens influenced the decision to proceed to RNU or UT in 73 cases $(73 / 117,62 \%)$. In the remaining 44 cases, the decision to proceed with RNU or UT was made based on clinical features, including size in 23 (23/44, $52 \%)$, multifocal disease in $3(3 / 44,7 \%)$, hydronephrosis or other imaging findings $(3 / 44,7 \%)$, presence in an area that is difficult to access endoscopically $(2 / 44,5 \%)$, or presence of residual/recurrent tumor despite therapy $(5 / 44,11 \%)$. In the remaining $8(8 / 44,18 \%)$ cases, there was a combination of more than one of the previously listed clinical features that influenced the decision for resection.

\subsection{Histolgic Features of Resections}

The clinicopathologic resection characteristics are summarized in Table 2. Tumor size information was available in 112 resections (out of the 117 resections, 96\% cases). In the cases where there were was multifocal disease and multiple measurements of foci of carcinoma was taken, the largest size was 
recorded. Overall, the average recorded tumor size was $3.6 \mathrm{~cm}$ (range $0.15-22.4 \mathrm{~cm}$ ). The majority of the surgically resected tumors ( $n=101,101 / 117,86 \%)$ showed papillary architecture; however, $6(6 / 101$, $6 \%$ ) of these resections demonstrated both inverted and papillary growth. In 5 resections (5/117, 4\%) the tumor showed only inverted architecture. Urothelial carcinoma in situ was the only disease on resection in 3 cases $(3 / 117,3 \%)$. Invasive carcinoma without a papillary component was present on resection in 8 cases $(8 / 117,7 \%)$. Fifty-two $(52 / 117,44 \%)$ cases at the time of resection demonstrated noninvasive urothelial carcinoma, out of which 24 (24/52, 46\%) were low-grade and the remainder highgrade. Sixty-five cases $(65 / 117,56 \%)$ demonstrated invasive urothelial carcinoma; 13 (13/65, 20\%) demonstrated presence of divergent histologic features. Divergent histologic features were reported only for invasive tumor, and the divergent features identified included squamous features in $7(7 / 13$, $54 \%)$ cases, micropapillary in $4(4 / 13,31 \%)$ cases, sarcomatoid in $2(2 / 13,15 \%)$, glandular in $2(2 / 13$, $15 \%)$, neuroendocrine in $1(1 / 13,8 \%)$, and nested in 1 case $(1 / 13,8 \%)$. Three resections had multiple divergent features within the same tumor. In terms of pathologic stage (utilizing AJCC $7^{\text {th }}$ edition [11]), pTa was the most common, occurring in $48(48 / 117,41 \%)$ resections; the remainder of the cases included 3 (3/117, 3\%) pTis, 24 (24/117, 21\%) pT1, 12 (12/117, 10\%) pT2, 26 (26/117, 22\%) pT3, and 3 (3/117, 3\%) pT4 (Table 3).

\subsection{Histologic Features of Preoperative Biopsies}

Among the 101 resections with pre-operative endoscopic biopsies available for review, 14 (14/101, $14 \%$ ) biopsies (from 14 patients) were negative for neoplasm. Nine of these biopsies were benign and/or reactive, including 6 with fragments of benign urothelium, 1 with benign renal parenchyma only, and 2 with granulation tissue. Of the remaining non-neoplastic biopsies (5), 1 did not survive processing, 1 showed only rare epithelial cells, 1 showed acellular debris, 1 showed stroma with crush artifact, and 1 showed cauterized urothelium with focal keratinizing squamous metaplasia. Renal pelvis biopsies lacking neoplastic diagnoses included $13 \%$ (7/54) of ureteroscopic biopsies and $13 \%(1 / 8)$ of percutaneous biopsies. Ureter biopsies lacking neoplastic diagnoses included 24\% (5/21) from the distal ureter, $0 \%(0 / 8)$ from the mid ureter, and $10 \%(1 / 10)$ from the proximal ureter. Photomicrographs of representative non-diagnostic biopsies are shown in Figure 1 . The remaining 87 resections $(87 / 101$, $86 \%$; from 83 patients) had pre-operative endoscopic upper urinary tract biopsies with neoplastic diagnoses. These included 23 noninvasive low-grade papillary urothelial carcinoma $(23 / 87,26 \%), 4$ urothelial carcinoma in situ (4/87, 5\%), 36 noninvasive high-grade papillary urothelial carcinoma (36/87, $41 \%)$, and 24 invasive high-grade papillary urothelial carcinoma (24/87, 28\%). Divergent histology was identified in one biopsy. $74 \%$ (75/101) of biopsies had subepithelial tissue present for evaluation. The biopsy findings are summarized in Table 4.

67 (67/87, 77\%) diagnostic biopsies had subepithelial tissue present for evaluation. These included $77 \%$ (36/47) ureteroscopic biopsies from renal pelvis, $100 \%$ (7/7) percutaneous biopsies from renal pelvis, $75 \%(12 / 16)$ ureteroscopic biopsies from distal ureter, 63\% (5/8) ureteroscopic biopsies from mid ureter, and $78 \%$ (7/9) biopsies from proximal ureter. Definitive muscularis propria was present in $4 \%$ $(2 / 47)$ of ureteroscopic biopsies from renal pelvis, $19 \%$ (3/16) from distal ureter, $0 \%(0 / 8)$ from mid ureter, and $0 \%(0 / 9)$ from proximal ureter. 


\subsection{Concordance between Preoperative biopsy and subsequent resesction}

The concordance rates of the 87 diagnostic biopsies with subsequent RNU or UT grade, invasion and presence of divergent features are shown in Table 5. Overall, 11\% (10/87) biopsies demonstrated a change in grade which included 3 from noninvasive low-grade papillary urothelial carcinoma to noninvasive high-grade papillary urothelial carcinoma (3/10, 30\%), 4 changed from noninvasive lowgrade papillary urothelial carcinoma to invasive high-grade urothelial carcinoma (4/10,40\%), and 3 were downgraded from noninvasive high-grade papillary urothelial carcinoma to noninvasive low-grade papillary urothelial carcinoma (3/10, 30\%). All 33 ureter biopsies showed concordant grade on biopsy and resection; however, grade was increased at the time of resection for 7 renal pelvis UTUC and decreased for 3 renal pelvis UTUC. Overall, 30\% (26/87) of cases with diagnostic biopsies were upstaged from noninvasive to invasive at the time of resection, including 6 noninvasive low-grade papillary urothelial carcinoma to invasive urothelial carcinoma (6/26, 23\%; 2 low-grade and 4 high-grade), 18 noninvasive high-grade papillary urothelial carcinoma to invasive urothelial carcinoma (18/26,69\%), and 2 urothelial carcinoma in situ to invasive urothelial carcinoma $(2 / 26,8 \%)$. Of the 18 cases reclassified from noninvasive high-grade papillary urothelial carcinoma on biopsy to invasive urothelial carcinoma on resection, 39\% (7/18) patients had previously undergone cystectomy for urothelial carcinoma. The frequency of prior cystectomy was significantly greater in this upstaged group as compared to the biopsy-resection pairs with concordant invasive $(2 / 24,8 \%)$ and noninvasive $(4 / 37,11 \%)$ carcinoma (chi square statistic $8.6, p=0.014)$. Significant differences in other pre-operative variables between these groups were not identified.

\subsection{Discordance between biopsies and resections}

$26 \%$ (14/54) of renal pelvis UTUC with diagnostic biopsies (12 ureteroscopic, 2 percutaneous) were upstaged from noninvasive to invasive at the time of resection. Among the tumors that were invasive on resection but noninvasive on ureteroscopic biopsy, $83 \%$ (10/12) of biopsies included subepithelial tissue. In contrast, $74 \%$ (26/35) renal pelvis ureteroscopic biopsies that showed concordant invasion status on resection included subepithelial tissue. Underlying renal parenchyma was present in all percutaneous renal pelvis biopsies. $36 \%$ of ureter UTUC with diagnostic biopsies (12/33) were upstaged from noninvasive to invasive at the time of resection; 5 biopsies were from distal ureter, 4 from mid ureter, and 3 from proximal ureter. There was no statistically significant difference in the rate of upstaging for ureter UTUC as compared to renal pelvis UTUC. Subepithelial tissue was present in $80 \%$ (4/5) upstaged biopsies from distal ureter versus $73 \%$ (8/11) with concordant invasion status, $25 \%$ (1/4) upstaged biopsies from mid ureter versus $100 \%(4 / 4)$ with concordant invasion status, and $33 \%(1 / 3)$ upstaged biopsies from proximal ureter versus $100 \%(6 / 6)$ with concordant invasion status. Photomicrographs of representative cases where the grade or presence of invasion was changed from biopsy to resection are shown in Figure 2.

Twenty-one cases of UTUC had pre-operative biopsies with neoplastic diagnoses, but no pre-operative pathologic material suggestive of high-grade disease (no invasion, no high-grade biopsy, no suspicious or positive cytology). Five cases including 1 ureter UTUC and 4 renal pelvis UTUC were invasive on resection only. The ureter UTUC that was upstaged at the time of resection had negative cytology but showed 
radiologic evidence of hydronephrosis. Two renal pelvis UTUC that were upstaged at the time of resection had atypical cytology; the other 2 renal pelvis UTUC did not have cytology material available. Six renal pelvis UTUC were called high-grade on resection alone; of these, only 1 had cytology, which was atypical.

\subsection{Preoperative Upper Tract Cytology}

Fifty-four resections had ipsilateral pre-operative upper urinary tract cytology specimens obtained within the year prior to resection and available for review. Cytologic diagnoses were correlated with diagnoses from 41 surgical resections of high-grade UTUC from 40 patients, 1 surgical resection of urothelial carcinoma in situ from 1 patient, and 12 surgical resections of low-grade UTUC from 12 patients. The majority of resections with high-grade UTUC (36/41, 88\%) had abnormal cytology results prior to surgery, including $12(12 / 36,33 \%)$ positive, 12 (12/36, 33\%) suspicious and 12 (12/36, 33\%) atypical diagnoses. The resection with UCIS had suspicious pre-operative cytology. While many resections with low-grade UTUC had negative pre-operative cytology $(5 / 12,42 \%)$, abnormal results included $5(5 / 12,42 \%)$ atypical, $1(1 / 12,8 \%)$ suspicious, and $1(1 / 12,8 \%)$ positive diagnoses. Calculated sensitivity and specificity values for detection of high-grade urothelial carcinoma are displayed in Table 6.

\subsection{Patient Outcomes}

Of the 87 resections with pre-operative neoplastic diagnoses, the biopsy grade was concordant with subsequent resection grade in 77 cases. Of these 77 patients, $32(32 / 77,42 \%)$ patients had recurrence of disease, $20(20 / 77,26 \%)$ developed metastasis and $27(27 / 77,35 \%)$ of patients died. In the 7 cases where the biopsy was low-grade and the resection was high-grade disease ( 3 noninvasive, 4 invasive), 0 $(0 / 7,0 \%)$ patients had recurrence of disease, $2(2 / 7,29 \%)$ developed metastasis and $2(2 / 7,29 \%)$ died. In the 3 cases where the biopsy was high-grade and the subsequent resection was low-grade, 1 patient $(1 / 3,33 \%)$ had recurrence of disease, $0(0 \%)$ patients developed metastates and $0(0 \%)$ patients died. Sixty-one patients had concordant invasion status on biopsy and resection. Of the 24 cases with invasive disease on both biopsy and resection (24/61 with concordant invasion status, 39\%), 10 developed recurrence (10/24, 42\%), 14 metastasis (14/24, 58\%), and 14 died (14/24, 58\%). Of the 37 cases with noninvasive disease on both biopsy and resection (37/61,61\%), 13 developed recurrence $(13 / 37,35 \%)$, 1 metastasis $(1 / 37,3 \%)$, and 6 died $(6 / 37,16 \%)$. Twelve cases with noninvasive carcinoma on biopsy were reclassified as T1 after resection of which $6(6 / 12,50 \%)$ recurred, 4 (4/12, 33\%) developed metastasis, and $5(5 / 12,42 \%)$ died. Fourteen cases with noninvasive carcinoma on biopsy were reclassified as muscle invasive disease (pT2 or higher) after resection; of these, 4 (4/14, 29\%) recurred, 3 $(3 / 14,21 \%)$ developed metastasis, and $4(4 / 14,29 \%)$ died. Eight patients had percutaneous biopsies of the renal pelvis; of these, $2(2 / 8,25 \%)$ developed recurrence ( 1 in urinary bladder, 1 in urinary bladder and contralateral ureter) and $2(2 / 8,25 \%)$ metastasized. Outcome information is summarized in Table 7.

\section{Discussion:}

Clinical decision-making in patients suspected to have UTUC remains a substantial challenge due to the technical limitations of upper urinary tract biopsy and cytology. Yet, these data indicate that the decision to proceed to RNU or UT for treatment of UTUC was often based on biopsy and cytology. 
Although these provide a relatively accurate assessment of the tumor grade at the time of resection, the invasive component of invasive tumors is often not represented on biopsy.

In line with our results, previous studies have shown high concordance of grade reported on ureteroscopic biopsy and resection. Rojas et al., reported grade concordance in $92.6 \%$ of cases, with discordant cases most often being upgraded on resection. [12] In the study by Rojas et al., biopsy volume did not affect assessment of tumor grade. Chitale et al., reported $74 \%$ overall concordance between biopsy and resection in a small cohort $(n=19)$; the only patient with discordant tumor grade was upgraded on resection. [13] Of note, however, the discordant tumor was reclassified from World Health Organization (WHO) grade 2 to WHO grade 3, so both specimens would be considered to be high-grade in nature by current WHO recommendations. Dev et al., also reported grade on a three-point scale; however, there was $90 \%$ concordance between biopsy and resection grade if grades 2 and 3 are reassigned to the high-grade category. [7] Because undergrading of tumor on upper tract biopsy is common, intensive follow-up is needed to ensure that high-grade tumor is not present. [14] Other groups have also reported from 63 to $>90 \%$ grade concordance. $[15,16,17,18,19]$

Upper urinary tract biopsies often provide insufficient material to assess for invasion. In our cohort, surgical resections resulted in reclassification of tumor invasion status in nearly one-third (30\%) of cases. Stage assessment using ureteroscopic biopsy may be difficult. [2] Upper tract biopsy samples are often superficial due to the small size of available tools for biopsy. $[16,19]$. In our study, lamina propria (or renal parenchyma) was present in $77 \%$ of biopsies with a neoplastic diagnosis. Lamina propria (or renal parenchyma) was present in $77 \%$ of cases where the biopsy and resection grades were concordant and $80 \%$ of cases where the biopsy and resection invasion was concordant. However, among biopsies from mid or proximal ureter, subepithelial tissue was less likely to be present in those cases that were called noninvasive on biopsy but invasive on resection. Although it has been proposed that accurate staging may be more difficult with larger tumors, the mean tumor size was larger in the concordant $(4.4 \mathrm{~cm})$ cohort in comparison to the upstaged $(3.6 \mathrm{~cm})$ group in our study. Among tumors diagnosed as noninvasive high-grade papillary urothelial carcinoma on biopsy and invasive high-grade urothelial carcinoma on resection, mean size was $2.8 \mathrm{~cm}$. Rojas et al., reported stage concordance in $43 \%$ of cases, while the other $57 \%$ were upstaged. [12] In their cohort, $59 \%$ of biopsies contained subepithelial connective tissue. Smith et al., found a similar rate of stage concordance. [17] Chitale et al., reported $16 \%$ of tumors showing invasion at the time of resection did not have invasion detected on biopsy, while $5 \%$ showed downstaging. [13] Guarnizo et al., found that biopsies were approximately $63 \%$ accurate in staging of UTUC ( $50 \%$ for renal pelvis and $71 \%$ for ureter). [16] Presence of high-grade tumor generally prompts definitive resection whether or not invasion is present, so this may not represent a significant limitation. However, some authors advocate for more conservative therapy of small, solitary noninvasive tumors, particularly when the patient's contralateral kidney is compromised. [20] In such instances, accurate assessment of the invasion status of the tumor is necessary. Modern radiologic techniques lack the sensitivity to make this distinction as well. [21] Notably, prior radical cystectomy for urinary bladder urothelial carcinoma may be a signal to treat more aggressively. $39 \%$ (7/18) UTUC reclassified from noninvasive high-grade papillary urothelial carcinoma on biopsy to invasive urothelial carcinoma on resection were seen in patients who had previously undergone cystectomy. Patients had 
prior cystectomy in only 8\% (2/24) UTUC with invasion on both biopsy and resection and $11 \%(4 / 37)$ UTUC without invasion on either biopsy or resection. Of the 8 patients in our cohort who underwent percutaneous biopsy of the renal pelvis, none had recurrences along the needle tract.

In our cohort, $14 \%$ of upper urinary tract biopsies failed to detect a neoplasm that was subsequently resected. As described above, the non-diagnostic biopsies in this cohort were either due to negative biopsies (benign or reactive urothelium or normal renal parenchyma) or inadequate sampling. Similarly, $87 \%$ of the 75 upper urinary tract biopsies in the cohort reported by Dev et al., demonstrated UTUC. [7] In our study, the biopsies that failed to detect neoplasm were slightly more commonly from the renal pelvis (57\%). These findings are similar to a previous study which demonstrated that almost one in four renal pelvis biopsies had inadequate tissue for a definitive diagnosis. [8] Common issues preventing definitive diagnosis included scant tissue, absence of papillary fronds, crush artifact, and distorted architecture. [8] Chen et al., reported that the sensitivity of ureteroscopic biopsy/cytology to detect recurrence after UTUC resection is $93.4 \%$. [22]

Previous studies have shown that voided urine cytology is less sensitive for diagnosis of UTUC than it is for diagnosis of urinary bladder UC; therefore, direct sampling from the upper urinary tract is preferable. [23] A recent meta-analysis of articles comparing upper tract cytology to resection and/or biopsy diagnoses demonstrated $55 \%$ sensitivity and $91 \%$ specificity. [9] Sensitivity of positive upper tract urine cytology has been reported to be as high as $81 \%$ in some cohorts. [10] The sensitivity of a positive upper tract cytology specimen for high-grade UC (HGUC) is $29 \%$ in this study, with specificity of $92 \%$. When both positive and suspicious diagnoses are included, there is a sensitivity of $58 \%$ and specificity of $83 \%$ for HGUC. With inclusion of any abnormal cytology diagnosis, the sensitivity increases to $88 \%$, although specificity drops to $42 \%$. Skolarikos et al., reported that tumors that were noninvasive on biopsy but had positive cytology were more likely to show invasion at the time of resection. [19] Williams et al., similarly reported an increased positive predictive value of muscle invasive disease in those patients with positive cytology, although this result did not achieve statistical signifiance. [18] In our cohort, there was not a significant difference in the rates of positive and suspicious cytology between the groups that were upstaged on resection compared to biopsy (4/10, 40\%) and concordant $(11 / 24,46 \%)$ groups.

Strengths of this study include the use of a large cohort of patients from a single tertiary care academic center, who underwent RNU or UT for UTUC, with available clinical follow-up. Limitations of the study include the fact that only in-house biopsy and cytology specimens were available for re-review, and therefore outside specimens were not available for pathologic assessment. On a related note, the patient population at our tertiary care center may not necessarily be representative of the general population. Additionally, our cohort was selected based on the presence of cancer at the time of the resection (acting as the gold standard for diagnosis); patients who received more conservative treatment were therefore not included. 
In conclusion, although upper urinary tract biopsy has significant technical limitations, a substantial proportion of specimens demonstrate presence of malignant neoplasm and grade concordance is high between biopsy and resection specimens. Upper urinary tract biopsies are often inadequate for assessment of invasion status. Despite the significant subset of cases with reclassification of grade and/or invasive status at the time of resection, most adverse patient outcomes were seen in cases with concordant grade and invasive status on the biopsy and resection. 


\section{References:}

1. Siegel RL, Miller KD, Jemal A. Cancer statistics, 2018. CA Cancer J Clin. 2018;68(1):7-30.

2. Roupret M, Babjuk M, Comperat E, et al. European Association of Urology Guidelines on Upper Urinary Tract Urothelial Carcinoma: 2017 Update. Eur Urol 2018;73(1):111-122.

3. Raab SS, Grzybicki DM, Vrbin CM, Geisinger KR. Urine cytology discrepancies: frequency, causes, and outcomes. Am J Clin Pathol 2007;127(6):946-953.

4. Umiker W. Accuracy of cytologic diagnosis of cancer of the urinary tract. Acta Cytol 1964;8:186-193.

5. Kern WH. The grade and pathologic stage of bladder cancer. Cancer 1984;53:1185-1189.

6. Bagley DH, Huffman JL, Lyon ES. Flexible ureteropyeloscopy: diagnosis and treatment in the upper urinary tract. J Urol 1987;138:280-285.

7. Dev HS, Poo S, Armitage J et al. Investigating upper urinary tract urothelial carcinomas: a single centre 10- year experience. World J Urol 2017;35:131-138.

8. Tavora F, Fajardo DA, Lee TK. Small endoscopic biopsies of the ureter and renal pelvis pathologic pitfalls. Am J Surg Path 2009; 33:1540-1546.

9. Potretzke AM, Knight BA, Vetter JM et al. Diagnostic utility of selective upper tract urinary cytology: a systematic review and meta-analysis of the literature. Urology 2016;96:35-43.

10. Naib ZM. Exfoliative cytology of renal pelvic lesions. Cancer 1961;14:1085-1087.

11. Edge SB, Byrd DR, Compton CC, Fritz AG, Greene FL, Trotti A, (editors). AJCC cancer staging manual, 7th edition. France: Springer; 2010.

12. Rojas CP, Castle SM, Llanos CA, et al. Low biopsy volume in ureteroscopy does not affect tumor biopsy grading in upper tract urothelial carcinoma. Urol Oncol 2013;31:1696-1700.

13. Chitale S, Mbakada R, Irving S, Burgess N. Nephroureterectomy for transitional cell carcinoma - the value of pre-operative histology. Ann R Coll Surg Engl 2008;90:45-50.

14. Roupret M, Babjuk M, Comperat E, et al. European Association of Urology guidelines on upper urinary tract urothelial cell carcinoma: 2015 update. Eur Urol 2015;68:868-879.

15. Keeley FX, Klup DA, Bibbo M et al. Diagnostic accuracy of ureteroscopic biopsy in upper tract transitional cell carcinoma. J Urol 1997;157:33-37.

16. Guarnizo E, Pavlovich CP, Seiba M, et al. Ureteroscopic biopsy of upper tract urothelial carcinoma: improved diagnostic accuracy and histopathological considerations using a multi-biopsy approach. J Urol 2000;163:52-55.

17. Smith AK, Stephenson AJ, Lane BR et al. Inadequacy of biopsy for diagnosis of upper tract urothelial carcinoma: implicartions for conservative management. Urology 2011;78(1) 82-86. 
18. Williams SK, Denton KJ, Minervini A, et al. Correlation of upper-tract cytology, retrograde pyelography, ureteroscopic appearance and ureteroscopic biopsy with histologic examination of uppertract transitional cell carcinoma. J Endourol 2008;22(1):71-76.

19. Skolarikos A, Griffiths TRL, Powell PH et al. Cytologic analysis of ureteral washings is informative in patients with grade 2 upper tract TCC considering endoscopic treatment. Urology 2003;61:146-150.

20. Ziegelbaum M, Novick AC, Streem SB, Montie JE, Pontes JE, Straffon RA. Conservative surgery for transitional cell carcinoma of the renal pelvis. J Urol 1987;138:1146-1149.

21. McKoy JG, Honda H, Reznicek M, Williams RD. Computerized tomography for detection and staging of localized and pathologically defined upper tract urothelial tumors. J Urol 1991;146:1500-1503.

22. Chen GL, El-Gabry EA, Bagley DH. Surveillance of upper urinary tract transitional cell carcinoma: the role of ureteroscopy, retrograde pyelography, cytology and urinalysis. J Urol 2000;164:1901-1904.

23. Messer J, Shariat SF, Brien JC, et al. Urinary cytology has a poor performance for predicting invasive or high-grade upper-tract urothelial carcinoma. BJU Int 2011;108:701-705. 


\section{FIGURE LEGENDS:}

Figure 1. Histologic Examples of Non-Diagnostic Biopsies (Hematoxylin and Eosin, 100x). Nondiagnostic biopsies occurred in both the renal pelvis (A-D) and the ureter (E-F). Examples of biopsies that were considered non-diagnostic include those with: extensive crush artifact (A), scant amounts of acellular debris (B), clotted blood/fibrin with rare detached single cells (C), subepithelial connective tissue and granulation tissue only with no epithelial component present (D), ulcerated granulation tissue (E) and scant urothelium with reactive changes (F).

Figure 2. Examples of Discordant Biopsies and Resections (Hematoxylin and Eosin, 200x). A-B. An example of a case in which the biopsy $(A)$ was called noninvasive low-grade UCa and the resection (B) was called noninvasive high-grade UCa. C-D. An example in which the biopsy (C) was called noninvasive high-grade UCa and the subsequent resection (D) was called noninvasive low-grade UCa. E-F. An example case in which the biopsy (E) was noninvasive high-grade UCa and the resection (F) was invasive high-grade UCa. 
Table 1. Clinical Cohort of 114 patients.

\begin{tabular}{|l|l|l|}
\hline \multirow{2}{*}{ Gender, $\mathbf{n}(\%)$} & Male & $85(75)$ \\
\cline { 2 - 3 } & Female & $29(25)$ \\
\hline \multirow{2}{*}{ Age at time of resection, years } & Range & $47-94$ \\
\cline { 2 - 3 } & Mean & 70 \\
\cline { 2 - 3 } & Median & 58 \\
\hline $\begin{array}{l}\text { Previous cystectomy for bladder } \\
\text { cancer, } \mathbf{n}(\%)\end{array}$ & $20(18)$ \\
\hline $\begin{array}{l}\text { Neoadjuvant chemotherapy, } \mathbf{n} \\
\text { (\%) }\end{array}$ & & $12(10)$ \\
\hline $\begin{array}{l}\text { Pre-resection upper tract } \\
\text { biopsy, } \mathbf{n} \text { (\%) }\end{array}$ & & $97(85)$ \\
\hline $\begin{array}{l}\text { Pre-resection upper tract } \\
\text { cytology specimen, } \mathbf{n} \text { (\%) }\end{array}$ & & $53(46)$ \\
\hline $\begin{array}{l}\text { High-grade biopsy or cytology } \\
\text { specimen }\end{array}$ & & $78(68)$ \\
\hline
\end{tabular}


Table 2. Pathologic Features of Upper Tract Resection Specimens.

\begin{tabular}{|c|c|c|}
\hline \multirow[t]{2}{*}{ Laterality, n (\%) } & Right & $44(38)$ \\
\hline & Left & $73(62)$ \\
\hline \multirow[t]{3}{*}{ Location, n (\%) } & Renal pelvis & $64(55)$ \\
\hline & Ureter & $34(29)$ \\
\hline & Renal pelvis and ureter & $19(16)$ \\
\hline \multirow[t]{2}{*}{ Focality, n (\%) } & Unifocal & $80(68)$ \\
\hline & Multifocal & $37(32)$ \\
\hline \multirow[t]{3}{*}{ Size, $\mathrm{cm}$} & Range & $0.15-22.4$ \\
\hline & Mean & 3.6 \\
\hline & Median & 2.7 \\
\hline \multirow[t]{2}{*}{ Grade, $\mathrm{n}(\%)$} & Low & $26(22)$ \\
\hline & High & $91(78)$ \\
\hline \multirow[t]{5}{*}{ Architecture, n (\%) } & Papillary & $95(81)$ \\
\hline & Inverted & $5(4)$ \\
\hline & Flat & $3(3)$ \\
\hline & Invasive & $8(7)$ \\
\hline & Multiple Patterns & $6(5)$ \\
\hline $\begin{array}{l}\text { Divergent Features Present, } n \\
\text { (\%) }\end{array}$ & & $13(20)$ \\
\hline Carcinoma in Situ Present, $\mathbf{n}(\%)$ & 7 & $44(38)$ \\
\hline $\begin{array}{l}\text { Angiolymphatic Invasion } \\
\text { Present, } \mathrm{n}(\%)\end{array}$ & & $16(14)$ \\
\hline \multirow[t]{3}{*}{ Final Surgical Margins, $\mathrm{n}(\%)$} & Negative & $111(95)$ \\
\hline & Positive for Dysplasia & $1(1)$ \\
\hline & Positive for Carcinoma & $5(4)$ \\
\hline
\end{tabular}


Table 3. Pathologic Stage of Upper Tract Resection Specimens.

\begin{tabular}{|l|l|l|}
\hline T Stage, $\mathbf{n}(\%)$ & Tis & $3(3)$ \\
\cline { 2 - 3 } & Ta & $49(42)$ \\
\cline { 2 - 3 } & T1 & $24(21)$ \\
\cline { 2 - 3 } & T2 & $12(10)$ \\
\cline { 2 - 3 } & T3 & $26(22)$ \\
\cline { 2 - 3 } & T4 & $3(3)$ \\
\hline \multirow{5}{*}{ N Stage, $\mathbf{n}(\%)$} & NX & $64(55)$ \\
\cline { 2 - 3 } & N0 & $46(39)$ \\
\cline { 2 - 3 } & N1 & $2(2)$ \\
\cline { 2 - 3 } & N2 & $5(4)$ \\
\hline M Stage, $\mathbf{n ~ ( \% ) ~}$ & MX & $110(94)$ \\
\cline { 2 - 3 } & M1 & $7(6)$ \\
\hline
\end{tabular}


Table 4. Pathologic Features of Upper Tract Biopsy Specimens with Neoplasm

\begin{tabular}{|l|l|l|}
\hline \multirow{2}{*}{ Laterality, $\mathbf{n}(\%)$} & Right & $31(36)$ \\
\cline { 2 - 3 } & Left & $56(64)$ \\
\hline \multirow{2}{*}{ Location, n (\%) } & Renal pelvis & $53(61)$ \\
\cline { 2 - 3 } & Ureter & $34(39)$ \\
\hline \multirow{2}{*}{ Grade, $\mathbf{n}(\%)$} & Low & $23(26)$ \\
\cline { 2 - 3 } & High & $64(74)$ \\
\hline Invasion Present, $\mathbf{n}(\%)$ & $24(28)$ \\
\hline $\begin{array}{l}\text { Divergent Features Present, } \mathbf{n} \\
\text { (\%) }\end{array}$ & & $1(1)$ \\
\hline $\begin{array}{l}\text { Subepithelial Tissue Present, } \mathbf{n} \\
\text { (\%) }\end{array}$ & & $67(77)$ \\
\hline $\begin{array}{l}\text { Muscularis Propria Present, } \mathbf{n} \\
\text { (\%) }\end{array}$ & & $5(6)$ \\
\hline
\end{tabular}


Table 5. Concordance of Diagnostic Biopsies with Subsequent Resection.

\begin{tabular}{|l|l|l|l|}
\hline & Discordant $\downarrow$ & Concordant & Discordant $\uparrow$ \\
\hline Grade, $\mathbf{n}$ (\% diagnostic biopsies) & $3(3)$ & $77(89)$ & $7(8)$ \\
\hline $\begin{array}{l}\text { Invasion, } \mathbf{n} \text { (\% diagnostic } \\
\text { biopsies) }\end{array}$ & $0(0)$ & $61(70)$ & $26(30)$ \\
\hline $\begin{array}{l}\text { Divergent Features, } \mathbf{n} \text { (\% } \\
\text { diagnostic biopsies for invasive } \\
\text { UCa) }\end{array}$ & $0(0)$ & $1(8)$ & $12(92)$ \\
\hline
\end{tabular}


Table 6. Sensitivity and specificity of pre-operative upper tract cytology specimens for high-grade urothelial carcinoma.

\begin{tabular}{|l|l|l|l|}
\hline Cytology Result & Number of cases $\mathbf{n = 5 3}$ & $\begin{array}{l}\text { Sensitivity for High } \\
\text { Grade UCA }\end{array}$ & $\begin{array}{l}\text { Specificity for High } \\
\text { Grade UCA }\end{array}$ \\
\hline Positive, $\mathbf{n}$ (\%) & $13(25)$ & 0.29 & 0.92 \\
\hline $\begin{array}{l}\text { Positive or Suspicious, } \\
\mathbf{n} \text { (\%) }\end{array}$ & $27(54)$ & 0.58 & 0.83 \\
\hline $\begin{array}{l}\text { Positive, Suspicious, or } \\
\text { Atypical, } \mathbf{n}(\%)\end{array}$ & $44(83)$ & & \\
\hline
\end{tabular}


Table 7. Patient Outcomes Based on Concordance of Diagnostic Biopsy and Resection Grade.

\begin{tabular}{|c|c|c|c|c|c|c|}
\hline & \multicolumn{3}{|c|}{ Grade } & \multicolumn{3}{|c|}{ Invasion } \\
\hline & $\begin{array}{l}\text { Concordant } \\
n=77\end{array}$ & $\begin{array}{l}\text { Discordant, } \\
\text { 个 time of } \\
\text { Resection } \\
n=7\end{array}$ & $\begin{array}{l}\text { Discordant, } \\
\downarrow \text { at time of } \\
\text { Resection } \\
n=3\end{array}$ & $\begin{array}{l}\text { Concordant } \\
n=61\end{array}$ & $\begin{array}{c}\text { Discordant, } \\
\begin{array}{c}\uparrow \text { time of } \\
\text { Resection } \\
n=26\end{array}\end{array}$ & $\begin{array}{l}\text { Discordant, } \\
\downarrow \text { at time of } \\
\text { Resection } \\
n=0\end{array}$ \\
\hline $\begin{array}{l}\text { Recurrence, } \\
\mathrm{n} \text { (\% } \\
\text { diagnostic } \\
\text { biopsies) }\end{array}$ & $32(42)$ & $0(0)$ & $1(33)$ & $23(38)$ & $10(38)$ & $0(0)$ \\
\hline $\begin{array}{l}\text { Metastasis, } \\
\mathrm{n} \text { (\% } \\
\text { diagnostic } \\
\text { biopsies) }\end{array}$ & $20(26)$ & $2(29)$ & $0(0)$ & $15(25)$ & $7(27)$ & $0(0)$ \\
\hline
\end{tabular}




\section{Highlights:}

- For upper tract urothelial carcinomas (UTUC), grade concordance between biopsy and resection is high

- In nearly one-third of cases, invasion is diagnosed on resection but not apparent on biopsy

- Subepithelial tissue is less commonly present in biopsies from the mid or proximal ureter

- UTUC in patients with prior cystectomy were more likely to show invasion on resection but not biopsy 


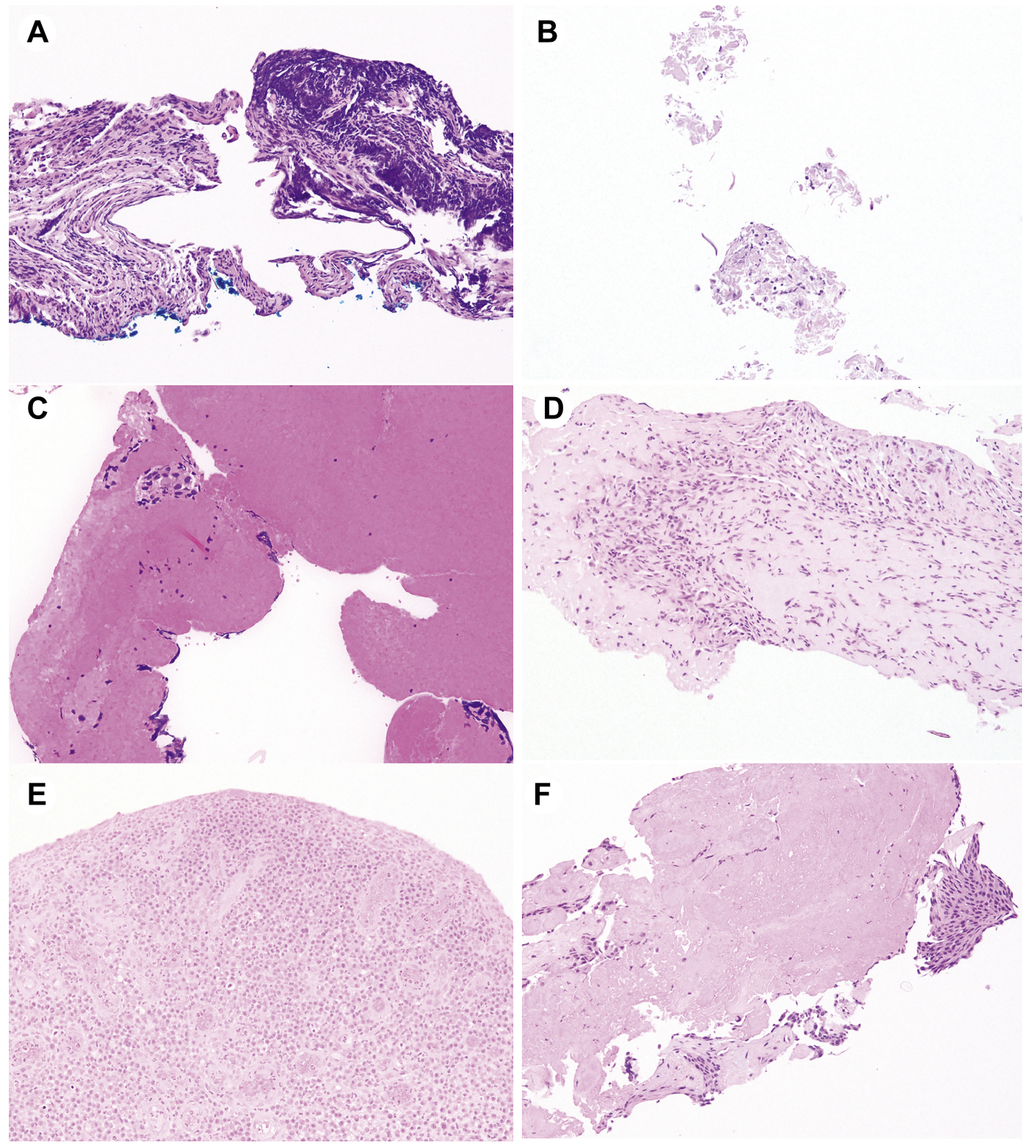

Figure 1 
A

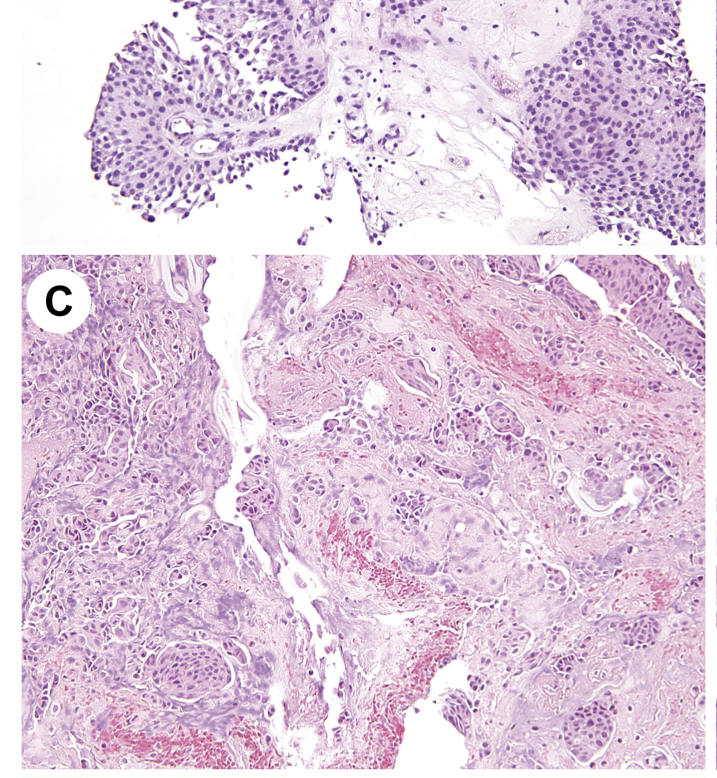

E

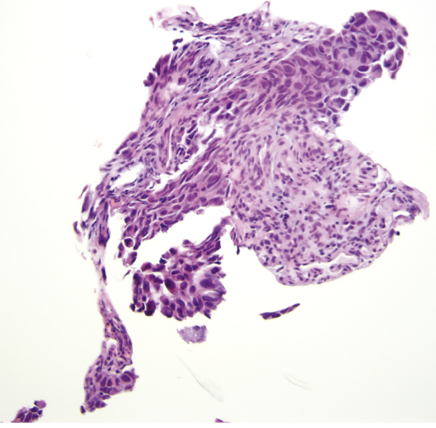

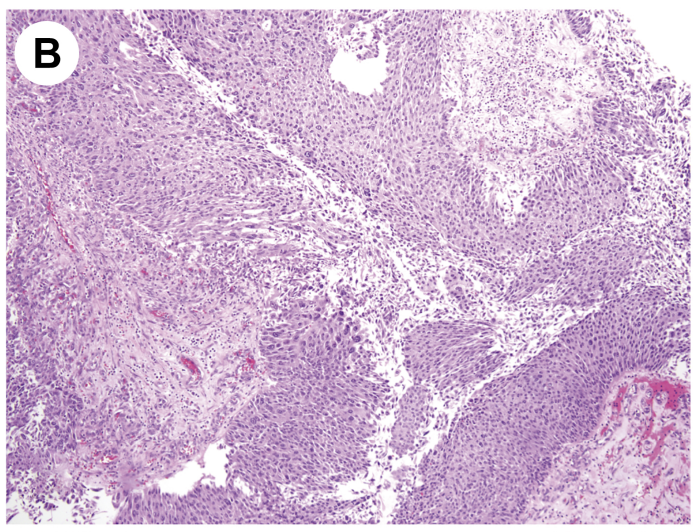

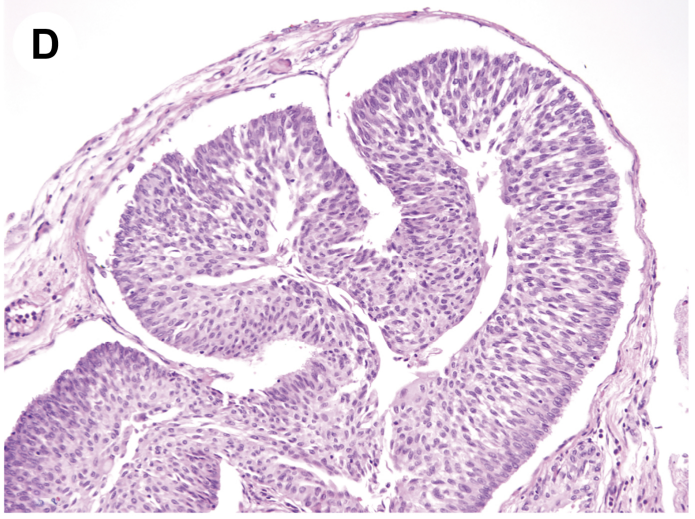

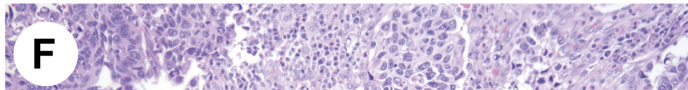

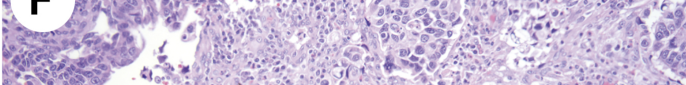

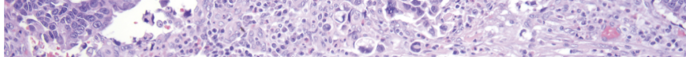

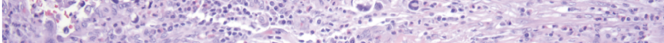

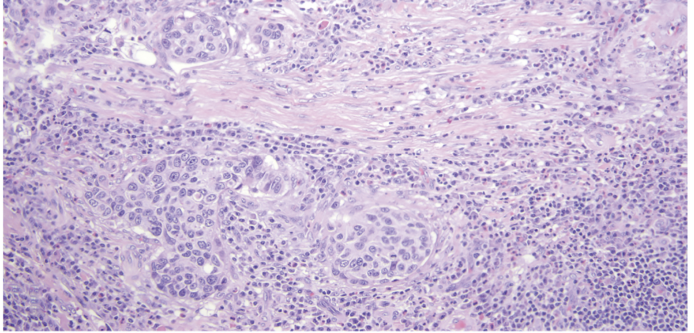

Figure 2 